\title{
Scopolamine Produces Larger Antidepressant and Antianxiety Effects in Women Than in Men
}

\author{
Maura L Furey*,', Ashish Khanna ${ }^{2}$, Elana M Hoffman' and Wayne C Drevets ${ }^{3}$ \\ 'Mood and Anxiety Disorders Program, NIMH, NIH, Bethesda, MD, USA; ${ }^{2}$ American University of the Caribbean School of Medicine, \\ Coral Gables, FL, USA and ${ }^{3}$ Laureate Institute for Brain Research, Tulsa, OK, USA
}

\begin{abstract}
Some antidepressant agents generate differential benefit based on gender. Blocking cholinergic muscarinic receptors using scopolamine produces robust and rapid antidepressant effects in males and females combined. This study evaluated if males and females differ in the antidepressant response magnitude following scopolamine administration. A total of 52 male and female outpatients meeting criteria for recurrent major depressive or bipolar disorder participated in a double-blind, randomized, placebo-controlled, crossover clinical trial involving seven i.v. infusions of placebo or scopolamine $(4 \mu \mathrm{g} / \mathrm{kg})$. Following a single-blind placebo lead-in, participants entered either a placebo-block/scopolamine-block or a scopolamine-block/placebo-block sequence. Each block included three sessions. Clinical ratings were acquired before each infusion and included the Montgomery-Asberg Depression Rating Scale (MADRS) and the Hamilton Anxiety Rating Scale (HAM-A). A treatment group $\times$ block interaction $(F=21.0, p<0.001)$ was observed in MADRS scores across gender, and the reduction was significant by the evaluation following the first scopolamine administration $(F=8.4, p=0.006)$. The treatment group $\times$ block interaction was also significant in males $(F=3.8, p=0.043)$ and females $(F=35.6, p<0.00$ I $)$ separately. A block $\times$ gender interaction $(F=7.4, p=0.009)$ indicated that the response magnitude was larger in women. The treatment $\times$ block interaction was significant for the HAM-A across gender $(F=12.0, p<0.00 \mathrm{I})$, and was significant for females $(F=24.9, p<0.00 \mathrm{I})$ but not for males $(F=1.3, p=0.30)$. When comparing the baseline block to study end, the block $\times$ gender interaction $(F=12.6, p=0.00 \mathrm{I})$ showed that the antianxiety response was greater in women. Men and women show a rapid antidepressant response following scopolamine, but the magnitude of response is larger in women than in men.

Neuropsychopharmacology (2010) 35, 2479-2488; doi:I0.1038/npp.2010.131; published online 25 August 2010
\end{abstract}

Keywords: depression; gender; antidepressant; antimuscarinic; anticholinergic

\section{INTRODUCTION}

Major depressive disorder (MDD) is reported twice as often in women when compared with men (Goodnick et al, 2000). The basis for this gender difference remains unclear. Some propose that women are more willing to seek help and to report symptoms than are men (see review Frackiewicz et al, 2000), leading simply to a reporting bias. Others have suggested that gender-specific influences of socialization, acute stressors, or sexual assault may explain the higher prevalence of depression in women (Frackiewicz et al, 2000). Finally, biological theories suggest that differences in brain structure and/or function underlie the difference in prevalence. For example, estrogen and progesterone may influence depressive symptoms in women as these hor-

*Correspondence: Dr ML Furey, Mood and Anxiety Disorders Program, National Institute of Mental Health, NIH, I5K North Drive, Building I5K, Room I I5B, Bethesda, MD 20892, USA, Tel: + 301594 7773, Fax: + 301594 9959, E-mail: mfurey@mail.nih.gov

Received 18 June 20 I0; revised 16 July 20 I0; accepted I 8 July 2010 mones modulate levels of serotonin, norepinephrine, acetylcholine, and monoamine oxidase (Benmansour et al, 2009; Gupta et al, 2007; Sell et al, 2008; Zhang et al, 2006). Further evidence for the implication of these hormones in depression comes from studies showing that the incidence of depression is greater in women than in men during the reproductive years, but after menopause when levels of estrogen and progesterone remain low, the incidence of depression in women becomes less than that seen in men (Bebbington et al, 1998; Bland et al, 1988). Moreover, women experience an increased risk of a depressive episode in relation to hormonal triggers associated with reproductive events, including the premenstrual or postpartum periods (Steiner et al, 2003; Yonkers, 2003). Together, these findings support a biological contribution to the observed gender difference in the prevalence of depression.

Although this point remains contested (Hildebrandt et al, 2003; Pinto-Meza et al, 2006; Quitkin et al, 2001), a literature exists that argues that men and women respond differently to antidepressant pharmacotherapies. When differences are reported, women showed an enhanced 
response to selective serotonin reuptake inhibitors (SSRIs) $v s$ either the selective norepinephrine reuptake inhibitor, reboxetine, or the tricyclic antidepressants imipramine and maprotiline (which predominantly inhibits norepinephrine transporters), whereas men showed a better response to imipramine $v s$ SSRI and no difference in their response to reboxetine or maprotiline vs SSRI (Berlanga and FloresRamos, 2006; Kornstein et al, 2000; Martenyi et al, 2001). Moreover, gender-based differences in response to SSRIs seen in premenopausal women are absent in postmenopausal women (Berlanga and Flores-Ramos, 2006; Kornstein et al, 2000; Martenyi et al, 2001). The evidence that estrogen has a role in the regulation of the serotonergic system (Rubinow et al, 1998) is consistent with the findings that the enhanced response outcome to SSRIs is specific to premenopausal women. If in fact the response to antidepressant agents differs based on gender, this observation would provide additional support for the hypothesis that the difference in the prevalence of depression is biologically based, and would further suggest that men and women tend toward differences in the underlying neurobiology of a similar symptom complex.

An insight into the underlying neurobiology of depression and mechanistic explanations for diagnostic subgroups will benefit from expanding our knowledge and understanding of gender differences. Recently, we reported that the antimuscarinic agent, scopolamine, produced rapid and robust antidepressant effects in currently depressed male and female patients with MDD or bipolar disorder (BD) (Drevets and Furey, 2010; Furey and Drevets, 2006). The purpose of this study was to determine if gender-based differences exist in the antidepressant response to scopolamine.

\section{MATERIALS AND METHODS}

\section{Participants}

Volunteers between 18 and 45 years of age evaluated at the NIMH outpatient clinic were assessed for eligibility if they denied current nicotine use and met Diagnostic and Statistical Manual of Mental Disorders, Fourth Edition, Text Revision (DSM-IV-TR; American Psychiatric Association, 2000) criteria for recurrent MDD or BD, based upon an unstructured interview conducted by a psychiatrist and the Structured Clinical Interview for DSM-IV-TR (First et al, 1997). Exclusion criteria included exposure to psychotropic or other medications likely to affect CNS or cholinergic function within 3 weeks ( 8 weeks for fluoxetine), suicidal ideation, delusions or hallucinations, lifetime history of substance dependence or substance abuse within 1 year, medical or neurological disorders, abnormal electrocardiogram or blood pressure, narrow angle glaucoma, hypersensitivity to anticholinergic agents, hepatic dysfunction, electrolyte disturbance, HIV or hepatitis viral infection, or weight $>125 \mathrm{~kg}$. Pregnant or nursing females were also excluded.

\section{Study Design}

During each of seven sessions, subjects received a 15-min intravenous (i.v.) infusion of either a placebo (P) saline solution, or $4.0 \mu \mathrm{g} / \mathrm{kg}$ of scopolamine (S). A single-blind,

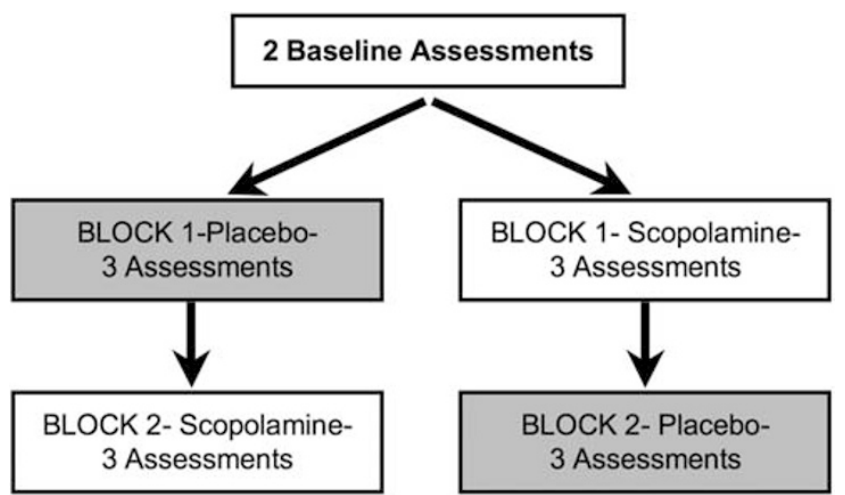

Figure I Blocked experimental design reflecting infusion series and assessment sessions for each of the two randomized patient groups. In block I, participants received a series of three infusions of either placebo or scopolamine; in block II, participants again received a series of three infusions and were crossed over to scopolamine or placebo.

lead-in session was used in which all subjects received a placebo infusion. As psychiatric assessments were obtained before session infusions, the lead-in placebo in session 1 allowed for a second baseline assessment to be obtained in session 2, before the session 2 infusion. Subsequently, individuals were randomized into either a $\mathrm{P} / \mathrm{S}$ or S/P double-blind, placebo-controlled, crossover design, whereby $\mathrm{P}$ constituted a block of three sessions during which participants received placebo and S comprised a block of three sessions during which participants received scopolamine (Figure 1). Follow-up interviews were obtained to provide the final assessment. Sessions were scheduled 3-5 days apart. Non-pregnancy was established before each session. Randomization sequences were determined by the NIH outpatient pharmacy and assigned by subject number at the time of consent. All staff involved in the administration of the infusion and the session assessments remained blind to allocation until participants completed the study.

\section{Assessment}

Before each infusion, psychiatric interviews were completed using the Montgomery and Asberg Depression Rating Scale (MADRS) (Khan et al, 2002), Hamilton Anxiety Rating Scale (HAM-A) (Hamilton, 1959), Young Mania Rating Scale (YMRS) (Young et al, 1978), and Clinical Global Impressions-Improvement (CGI-I) (Khan et al, 2002) scales. Visual analog scales (VAS) and the Profile of Mood State (POMS) (McNair et al, 1971) were administered at baseline and at 20, 60, 120 (VAS only), and $150 \mathrm{~min}$ relative to infusion start time, and blood samples were obtained at baseline and at $30,45,60,90,120$, and $150 \mathrm{~min}$ relative to infusion start time.

\section{Outcome Measures}

The antidepressant and antianxiety responses to scopolamine were evaluated by assessing changes in MADRS and HAM-A scores, respectively. The CGI assessed overall clinical improvement. Secondary outcome measures included the VAS and the POMS to assess acute changes 
in mood within each session. The YMRS was obtained to assess the possible development of manic symptoms.

Patients were characterized as achieving (Nierenberg and DeCecco, 2001): (1) full response ( $\geqslant 50 \%$ reduction in MADRS score from baseline); (2) partial response $(<50 \%$ but $\geqslant 25 \%$ reduction); or (3) nonresponse ( $<25 \%$ reduction). Patients achieving remission (post-treatment MADRS score $\leqslant 10$ ) were also identified.

\section{Scopolamine Assay}

Blood samples were centrifuged at 3000 r.p.m. and $4{ }^{\circ} \mathrm{C}$ for $10 \mathrm{~min}$, and the plasma transferred to polypropylene tubes, frozen, and stored at $-70^{\circ} \mathrm{C}$ until analysis. Scopolamine plasma levels were determined by CANTEST BioPharma Services, a Division of CANTEST (Burnaby, BC, Canada). Area under the curve (AUC) concentration from 30 to $150 \mathrm{~min}$ was estimated for each session. Repeated measures ANOVA (RM ANOVA) was used to evaluate session differences across genders, and between-group differences evaluated overall gender effects on AUC. As samples were processed in three different batches, batch was included as a covariate.

\section{Data Analysis}

A treatment group $(\mathrm{P} / \mathrm{S}$ vs $\mathrm{S} / \mathrm{P}) \times$ assessments $\mathrm{RM}$ ANOVA was performed to evaluate differences in change in MADRS, HAM-A, CGI-I, VAS, and the POMS. To provide a balanced design allowing for group $\times$ study block $\times$ repeated measures analyses, MADRS data were separated into a baseline block (assessments 1 and 2), and two experimental blocks. For each experimental block, the first and last measures were included in the analysis, so that experimental block I included assessments 3 and 5, and experimental block II included assessments 6 and follow-up. The treatment group $\times$ block analyses were used to test the hypotheses that scopolamine produces greater reductions in MADRS and HAM-A scores than placebo. When the RM ANOVA was significant, we calculated post hoc between- and withingroup $t$-tests in planned comparisons to identify significant effects on the outcomes measures in the presence of significant overall ANOVAs. Speed of response onset was evaluated using $t$-tests to compare the first assessment following the first scopolamine administration relative to placebo assessments for both the S/P and the P/S treatment groups. Paired $t$-tests were used to test the hypothesis that scopolamine reduced symptoms of depression and anxiety as indicated by within-group changes in clinical rating scores, and independent $t$-tests were used to test the hypothesis that the change in scale scores is greater during scopolamine than during placebo.

Treatment group $\times$ assessment $\mathrm{RM}$ ANOVA analyses were then performed within gender to characterize drug effects separately. Gender-based differences in the magnitude of treatment response were evaluated on the MADRS, HAM-A, CGI-I, VAS, and POMS by comparing the baseline block (assessments 1 and 2) with study end assessments (last 2 assessments). The $\chi^{2}$ was used to determine if the response rates observed following scopolamine treatment differed between men and women. Gender-based differences in scopolamine response were also considered regarding frequency of side effects using $\chi^{2}$, and magnitude of change in vital signs using RM ANOVA.

Secondary analyses using RM ANOVA were performed to evaluate the influence of diagnostic subgroups on treatment response to rule out the possibility that such subgroups were driving the observed gender effects. Subgroups included MDD $v s \mathrm{BD}$, and presence $v s$ absence of comorbid anxiety disorder.

\section{RESULTS}

\section{Patient Characteristics}

Outpatients were recruited from May 2004 through February 2010 at the NIMH (Supplementary Figure 1). Of 113 subjects assessed for eligibility, 59 were excluded for not meeting entrance criteria $(n=24)$ or refusing to participate $(n=35)$. In all, 54 patients met the entrance criteria and were randomized into treatment. One subject withdrew following the first infusion (single-blind placebo), and one subject dropped out after randomization but before session 1 , and hence these two subjects did not contribute any data to the analysis. Of the remaining 52 patients, 27 patients were randomized into the $\mathrm{P} / \mathrm{S}$ group, including 15 females and 12 males, and 25 into the $\mathrm{S} / \mathrm{P}$ group, including 16 females and 9 males. Thus, a total of 52 participants received the intended treatment, completed the protocol, and were included in all analyses. Data for 40 of these 52 participants were included in two previous publications (Drevets and Furey, 2010; Furey and Drevets, 2006). In cases where follow-up interviews could not be obtained for the assessment following session $7 \quad(n=8)$, analyses were performed using the last observation carried forward (LOCF). The characteristics of the treatment groups separated by gender are shown in Table 1 . The P/S and $\mathrm{S} / \mathrm{P}$ groups did not differ at baseline in MADRS $(\mathrm{F}=0.73$, $p=0.49)$ or HAM-A $(\mathrm{F}=0.95, p=0.40)$ scores; males and females did not differ at baseline in MADRS $(F=0.09$, $p=0.92)$ or HAM-A $(\mathrm{F}=1.3, p=0.29)$; and no treatment group $\times$ gender interaction was observed at baseline in MADRS $(\mathrm{F}=0.12, p=0.89)$ or HAM-A $(\mathrm{F}=0.15, p=0.86)$ scores.

Table I Baseline Characteristics of the P/S and S/P Groups, Separated by Females and Males

\begin{tabular}{|c|c|c|c|c|}
\hline & \multicolumn{2}{|c|}{ Females } & \multicolumn{2}{|c|}{ Males } \\
\hline & $\begin{array}{c}\text { P/S } \\
(n=15)\end{array}$ & $\begin{array}{c}\text { S/P } \\
(n=16)\end{array}$ & $\begin{array}{c}\text { P/S } \\
(n=I 2)\end{array}$ & $\begin{array}{c}\text { S/P } \\
(n=9)\end{array}$ \\
\hline Mean age+SD & $31.2 \pm 7.6$ & $35.7 \pm 7.6$ & $30.0 \pm 9.1$ & $32.8 \pm 10.2$ \\
\hline Number MDD/BD & $9 / 6$ & $12 / 4$ & $10 / 2$ & $7 / 2$ \\
\hline Baseline MADRS \pm SD & $31.1 \pm 4.7$ & $29.9 \pm 5.4$ & $32.3 \pm 5.3$ & $30.0 \pm 3.6$ \\
\hline Baseline HAM-A $\pm S D$ & $20.0 \pm 6.5$ & $22.6 \pm 7.6$ & $16.6 \pm 6.9$ & $19.2 \pm 9.7$ \\
\hline Chronic illness ( $>2$ years) & 8 & 9 & 7 & 7 \\
\hline Comorbid anxiety & 3 & 7 & 6 & 4 \\
\hline
\end{tabular}




\section{Outcome Indices}

Mean ( \pm SD) MADRS scores for the two treatment groups across all eight evaluations appear in Figure $2 \mathrm{a}$ in the groups combined across gender. The RM ANOVA showed a significant treatment group $\times$ block interaction $(\mathrm{F}=21.0$, $p<0.001$ ) (see Supplementary Materials for more detail). The treatment group $\times$ block interaction on MADRS scores showed a similar pattern as described above when considering men $(\mathrm{F}=3.8, p=0.043)$ and women $(\mathrm{F}=35.6$, $p<0.001$ ) separately (Figure $2 \mathrm{~b}$ and $\mathrm{c}$ ), indicating that both men and women showed significant improvement in depression severity following scopolamine treatment. Regarding changes from the baseline to experimental block $I$ in men alone, the $S / P$ group showed a within-group reduction in depression severity $(\mathrm{F}=15.1, p<0.005$; Cohen's $\mathrm{d}=1.71, \mathrm{CI}=-0.84$ to 5.36 ), but this change did not differ significantly from the change observed in the P/S group $(\mathrm{F}=0.97, p=0.34)$, suggesting that a larger sample size would have been needed to establish a drug effect that exceeded that seen with placebo. When comparing the baseline block to the study end in males and thus doubling the sample size, a reduction in MADRS is observed $(\mathrm{F}=34.3, p<0.001)$. The women in the $\mathrm{S} / \mathrm{P}$ group showed a within-group reduction in depression severity in the first experimental block relative to the placebo block $(\mathrm{F}=53.8$, $p<0.001)$, and the observed change differed significantly from the observed change in the $\mathrm{P} / \mathrm{S}$ group $(\mathrm{F}=14.1$, $p<0.001$; Cohen's $d=1.85, \mathrm{CI}=-0.55$ to 5.33 ), indicating that the drug effect exceeded the change seen during placebo. Moreover, this difference was significant at the first evaluation in the first experimental block $(t=6.1$, $p<0.001)$. When comparing the baseline block to the study end assessments, a block $\times$ gender interaction was also observed $(\mathrm{F}=7.4, p=0.009 ;$ Cohen's $\mathrm{d}$ males $=1.83$, $\mathrm{CI}=0.28-4.75$; Cohen's $\mathrm{d}$ females $=2.68, \mathrm{CI}=1.13-5.57$ ), indicating that the antidepressant response magnitude was greater in females than in males (Figure $2 \mathrm{~d}$ ).

In an effort to determine if diagnostic subgroups distributed differently across males and females are driving the gender effect on the magnitude of improvement on MADRS scores, we also considered antidepressant response relative to primary diagnosis (ie, MDD or $\mathrm{BD}$ ) and to the presence of comorbid anxiety disorders by comparing the baseline block to study end. No effect of block $\times$ diagnosis $(\mathrm{F}=0.12, \quad p=0.67)$ or block $\times$ comorbid anxiety disorder $(\mathrm{F}=0.07, p=0.80)$ was observed, nor did we see a block $\times$ diagnosis $\times$ gender interaction $(\mathrm{F}=1.4, p=0.24)$ or a block $\times$ comorbid anxiety $\times$ gender interaction $(\mathrm{F}=0.01$, $p=0.91)$.

Table 2 provides a summary of response outcome. By study end, 22 of 31 females experienced a full response (71\%) and 18 of 31 females experienced remission of symptoms $(58 \%)$, whereas 9 of 21 males showed a full response $(42 \%)$ and 6 of 21 males experienced remission of symptoms (28\%). At study end, 4 of 31 females showed nonresponse relative to baseline measures (13\%), whereas 7 of 21 males showed nonresponse (33\%). The proportion
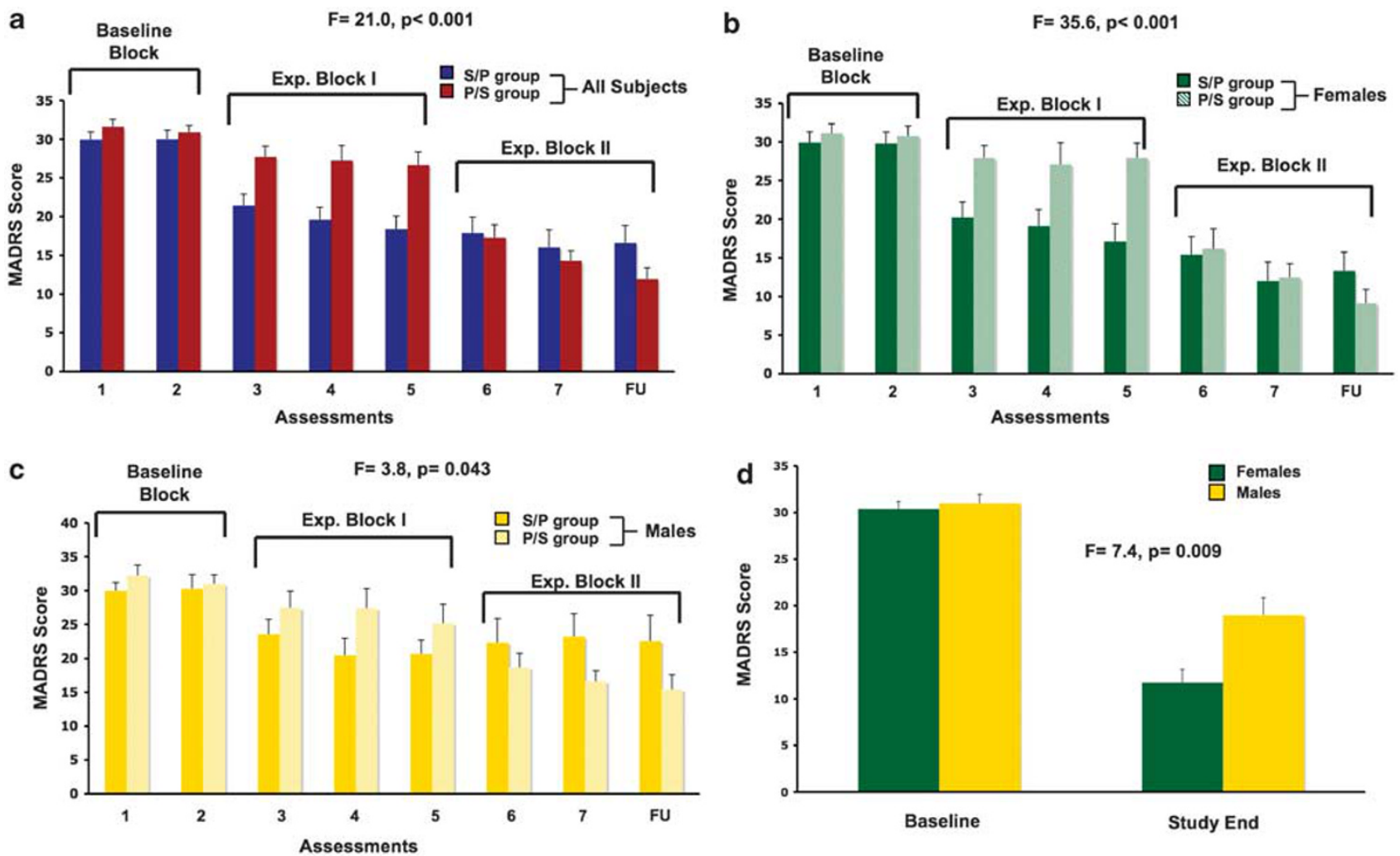

Figure 2 Mean MADRS scores ( $\pm \mathrm{SE}$ ) are shown for each of the seven assessments and the follow-up evaluation are presented for all subjects combined (a), as well as for females (b) and males (c) separately. Mean baseline and study end MADRS scores are also shown (d) separated into female and male subgroups. 
Table 2 Response Outcomes for Females and Males Treated with Scopolamine

\begin{tabular}{|c|c|c|c|}
\hline & $\begin{array}{c}\text { Baseline } \\
\text { block }\end{array}$ & Block I & Block 2 \\
\hline \multicolumn{4}{|l|}{ Females } \\
\hline \multicolumn{4}{|l|}{$P / S$ group $(n=15)$} \\
\hline Full response (>50\%) & 0 & 0 & $12(80 \%)$ \\
\hline Partial response (25-49\%) & । (7\%) & $3(20 \%)$ & $3(20 \%)$ \\
\hline Nonresponse & 14 (93\%) & $12(80 \%)$ & 0 \\
\hline Remission $^{\mathrm{a}}(\mathrm{MADRS} \leqslant 10)$ & 0 & 0 & $10(67 \%)$ \\
\hline \multicolumn{4}{|l|}{$S / P$ group $(n=16)$} \\
\hline Full response $(>50 \%)$ & 0 & $7(44 \%)$ & $10(63 \%)$ \\
\hline Partial response (25-49\%) & I (6\%) & $5(3 \mid \%)$ & $2(13 \%)$ \\
\hline Nonresponse & 15 (94\%) & $4(25 \%)$ & $4(25 \%)$ \\
\hline Remission (MADRS $\leqslant 10$ ) & 0 & $6(38 \%)$ & $8(50 \%)$ \\
\hline \multicolumn{4}{|l|}{ Males } \\
\hline \multicolumn{4}{|l|}{$P / S \operatorname{group}(n=12)$} \\
\hline Full response (>50\%) & 0 & $2(17 \%)$ & $6(50 \%)$ \\
\hline Partial response (25-49\%) & 0 & $3(25 \%)$ & $3(25 \%)$ \\
\hline Nonresponse & $12(100 \%)$ & $7(58 \%)$ & $3(25 \%)$ \\
\hline Remission (MADRS $\leqslant 10$ ) & 0 & । (8\%) & $4(33 \%)$ \\
\hline \multicolumn{4}{|l|}{$S / P$ group $(n=9)$} \\
\hline Full response $(>50 \%)$ & 0 & $2(22 \%)$ & $3(33 \%)$ \\
\hline Partial response (25-49\%) & | (| |\%) & $2(22 \%)$ & $2(22 \%)$ \\
\hline Nonresponse & $8(89 \%)$ & $5(56 \%)$ & $4(44 \%)$ \\
\hline Remission (MADRS $\leqslant 10$ ) & 0 & 0 & $2(22 \%)$ \\
\hline
\end{tabular}

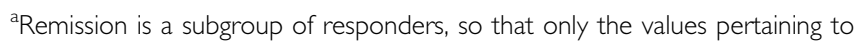
response sum to $100 \%$.

of men and women who showed a full response ( $v s$ a partial or nonresponse) differed $\left(\chi^{2}=4.11, p<0.05\right)$, with a larger proportion of women showing a full response following treatment with scopolamine. Similarly, the proportion of men and women who showed nonresponse ( $v s$ partial or full) to scopolamine trended toward significance $\left(\chi^{2}=3.13, p<0.07\right)$, with a larger proportion of men showing nonresponse to scopolamine than women.

The HAM-A scores showed a treatment group $\times$ block interaction when the gender data were combined $(\mathrm{F}=12.0$, $p<0.001)$, and this interaction was significant when considering only females $(\mathrm{F}=24.9, p<0.001)$ but not significant for only males $(\mathrm{F}=1.3, p=0.30)$. The females in the S/P group showed a reduction in HAM-A in the first experimental block relative to the baseline block $(\mathrm{F}=57.9$, $p<0.001)$ and this change differed from the change observed in the $\mathrm{P} / \mathrm{S}$ group $(\mathrm{F}=21.6, p<0.001)$, suggesting that the reduction observed in the $\mathrm{S} / \mathrm{P}$ group exceeded the change seen during placebo. This reduction was significant with the first evaluation in experimental block 1 when compared with baseline $(t=5.3, p<0.001)$. When comparing the baseline block to study end, the block $\times$ gender interaction was significant $(\mathrm{F}=12.6, p=0.001)$, indicating that the antianxiety response was greater in women than in men (Figure 3).

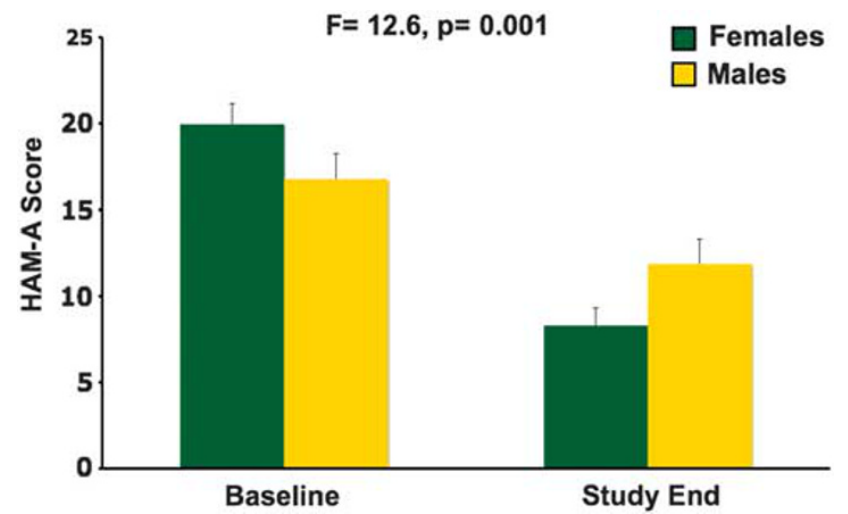

Figure 3 Mean baseline and study end HAM-A scores ( \pm SE) are shown separated into female and male subgroups.

To evaluate the possibility that subgroups are driving the gender effect on the improvement in HAM-A scores, we also analyzed response magnitude relative to diagnosis and comorbid anxiety disorders. No effect of block $\times$ diagnosis $(\mathrm{F}=0.84, p=0.44)$ or block $\times$ comorbid anxiety disorder $(\mathrm{F}=1.3, p=0.30)$ was observed. No block $\times$ diagnosis $\times$ gender interaction was observed $(\mathrm{F}=1.1, p=0.33)$, or a block $\times$ comorbid anxiety $\times$ gender interaction was observed $(\mathrm{F}=1.8, p=0.18)$.

Mean CGI-I scores are shown for the two treatment groups in Figure 4a. A treatment group $\times$ assessment interaction was observed $(\mathrm{F}=7.9, p<0.001)$. The $\mathrm{RM}$ ANOVA also showed a treatment group $\times$ block interaction $(\mathrm{F}=22.2, \quad p<0.001) \quad$ (see Supplementary Materials for more details). The treatment group $\times$ block interaction was significant for women alone $(\mathrm{F}=39.5, \quad p<0.001$; Figure $4 \mathrm{~b}$ ), and although this interaction was also significant for men alone $(\mathrm{F}=4.6, p=0.046)$; Figure $4 \mathrm{c})$, the treatment groups did not differ significantly at any single time point $(p>0.10$; with a trend in the final time point, $p=0.08$ ). Within females, the two treatment groups differed in the first evaluation in block I and this change in CGI-I score was greater in the S/P group when compared with baseline $(\mathrm{F}=8.7, p=0.006)$. Similarly, considering the transition from experimental block I to block II using evaluations 5 and 6 , the P/S group shows an improvement in CGI-I that is larger than the change seen in the S/P group $(\mathrm{F}=14.6, p=0.001)$. Comparing baseline to study end, a block $\times$ gender interaction is seen $(\mathrm{F}=5.8, p=0.02)$, indicating that overall clinical improvement was larger in women than in men (Figure $4 \mathrm{~d}$ ).

Autonomic measures during placebo and scopolamine, as well as changes in autonomic measures during scopolamine relative to placebo, were evaluated. As systolic blood pressure trended toward being higher overall in males $(\mathrm{F}=3.6, p=0.06)$ and specific time points were significantly higher in males $v s$ females under placebo (time point 5 , $t=2.7, p=0.01$; time point $8, t=2.4, p=0.02$ ), the analyses to determine scopolamine effects were performed on values reflecting delta in systolic blood pressure, so that systolic blood pressure during placebo was subtracted from systolic blood pressure during scopolamine. The change in systolic blood pressure observed on scopolamine relative to placebo did not differ based on gender $(F=0.12$, 

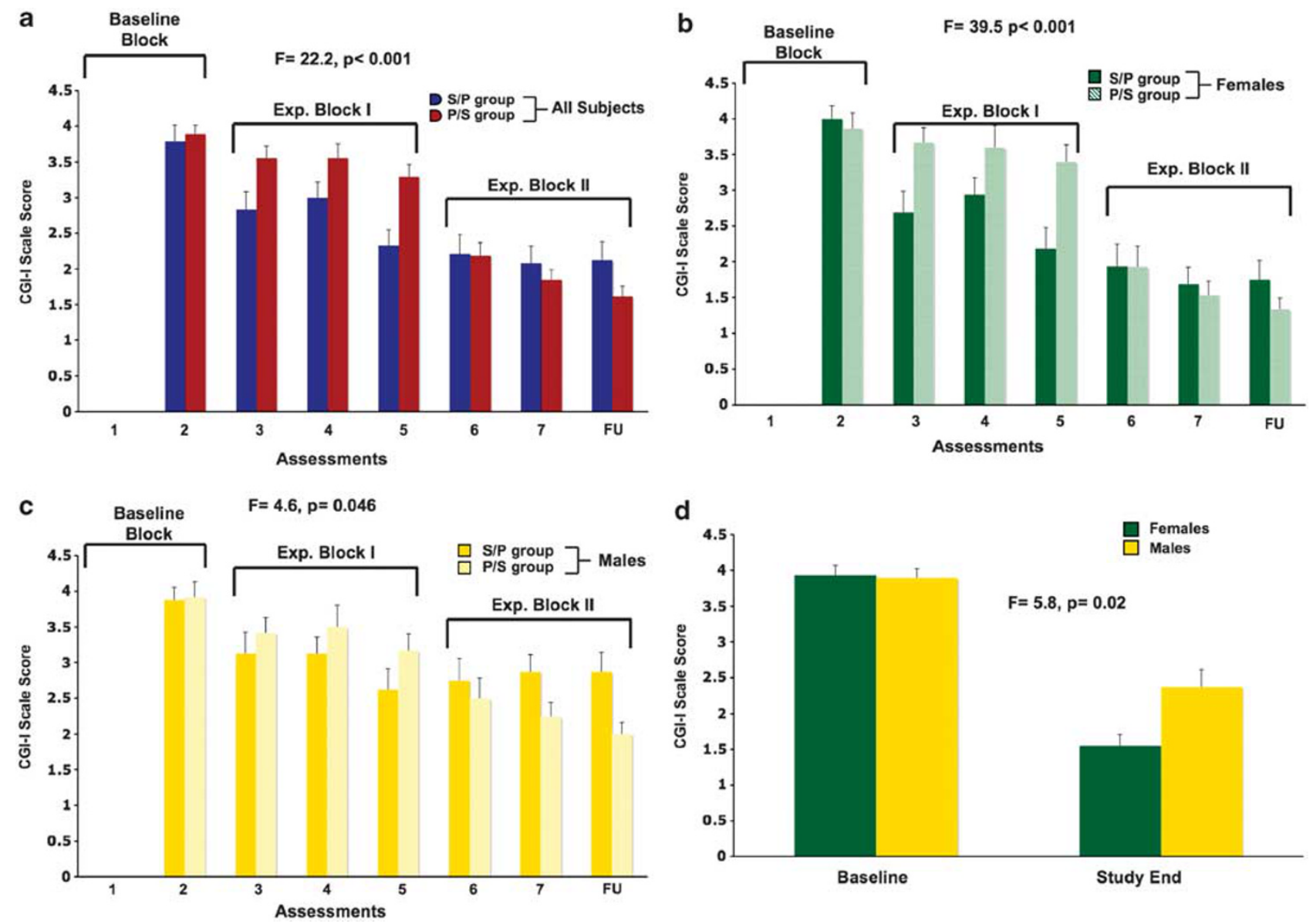

Figure 4 Mean CGI-I scores $( \pm$ SE) are shown for each of the seven assessments and the follow-up evaluation are presented for all subjects combined (a), as well as for females (b) and males (c) separately. Mean baseline and study end CGI-I scores are also shown (d) separated into female and male subgroups.

$p=0.73)$, although the difference at time point 5 was significant $(t=2.2, p=0.03)$. This effect was likely driven by the elevated measure obtained during placebo for time point 5 in males (reported above).

Diastolic blood pressure also tended to be higher in males $(\mathrm{F}=2.9, p=0.09)$, and specific time points were significantly higher in males $v s$ females under placebo (time point $5, t=2.40, p=0.02$; with trend level significance at time point $2, t=1.9, p=0.07$; and time point $3, t=2.0$, $p=0.052$ ), and thus the scopolamine effect was evaluated based on delta. The change in diastolic blood pressure during scopolamine relative to placebo showed no gender $(\mathrm{F}=1.7, p>0.20) \quad$ or gender $\times$ time $\quad(\mathrm{F}=0.80, p>0.20)$ effect. No gender difference was measured in heart rate during placebo $(\mathrm{F}=2.7, p=0.10)$, and no drug $\times$ gender $(\mathrm{F}=0.43, p>0.20)$ or drug $\times$ gender $\times$ time point interaction $(\mathrm{F}=0.84, p>0.20)$ was observed. No gender-based difference in the change in heart rate during scopolamine relative to placebo was observed $(\mathrm{F}=0.93, p>0.20)$.

Scopolamine was well tolerated and resulted in no medically serious adverse events. The frequency of reported side effects is presented in Table 3. No gender-based difference in the frequency of any side effect was observed $(p>0.10)$, except for fatigue where men reported fatigue more than women under placebo and scopolamine
Table 3 Reported Side Effects Following Placebo and Scopolamine Infusions, Separated for Females and Males

\begin{tabular}{lccccc}
\hline & \multicolumn{2}{c}{ Placebo } & & \multicolumn{2}{c}{ Scopolamine } \\
\cline { 2 - 3 } \cline { 5 - 6 } & $\begin{array}{c}\text { Females } \\
(\mathbf{n}=\mathbf{3} \mathbf{)})\end{array}$ & $\begin{array}{c}\text { Males } \\
(\mathbf{n}=\mathbf{2 2})\end{array}$ & & Females & Males \\
\hline Dizziness & 0 & 3 & & \\
Light-headed & 7 & 7 & & 20 & 11 \\
Blurred vision & 0 & 3 & & 18 & 13 \\
Drowsy & 9 & 1 & & 22 & 15 \\
Dry mouth & 14 & 7 & & 24 & 20 \\
Fatigue & 2 & 6 & & 2 & 7 \\
'Feel drugged' & 3 & 0 & & 7 & 8 \\
Nausea & 0 & 1 & & 0 & 1 \\
Nervousness & 1 & 3 & & 1 & 1 \\
Palpitations & 2 & 1 & & 2 & 0 \\
Irritability & 0 & 0 & 0 & 0 \\
Headache & 0 & 1 & 2 & 1 \\
Restlessness & 0 & 3 & 1 & 1 \\
Vertigo & 0 & 0 & 1 & 0 \\
\hline
\end{tabular}


$(p=0.04)$. No gender-based difference in AUC occurred across sessions $(\mathrm{F}=0.95, p>0.20)$ nor did the mean AUC differ based on gender $(t=0.67, p>0.20)$. The results from the VAS and POMS are discussed in Supplementary Material.

\section{DISCUSSION}

The results of this study demonstrate that men and women show a rapid antidepressant response following scopolamine, but the mean reduction in depression ratings was larger in women than in men. Scopolamine produced improvement in depression severity by the first assessment following the first administration of the drug in both gender groups; thus, the rapidity of the antidepressant response was comparable, but by study end the magnitude of response was greater in females than in males. In addition, a larger proportion of women showed a response to scopolamine $(71 \%)$ than did men $(38 \%)$, and thus the greater improvement was driven partially by the larger proportion of women who responded to scopolamine.

The absence of significant differences in the antidepressant response magnitude between MDD and BD diagnostic subgroups, as well as the absence of differences between patients with and without comorbid anxiety disorder, indicates that no such underlying subgroup effects are driving gender-based differences. Moreover, there was no interaction between these diagnostic subtypes and gender, further supporting the conclusion that the observed effects are based on gender differences and are not spurious findings driven by other factors.

A robust antianxiety response was observed exclusively in females, with males showed no significant improvement in anxiety ratings associated with drug administration (although this effect in males might become significant with a larger sample size). Thus, women show scopolamineinduced improvement in both the depression severity and anxiety, whereas men show modest improvement in depression severity.

The cholinergic system has been implicated in depression for decades by a variety of types of evidence (Janowsky et al, 1972, 1983, 1994; Janowsky and Overstreet, 1990), and has resurfaced as a potential target for novel therapeutics (Furey and Drevets, 2006; Janowsky et al, 1994; Overstreet et al, 1996, 1998). For example, in addition to the recent demonstration that this antimuscarinic agent has rapid antidepressant effects, several types of evidence suggest that muscarinic cholinergic receptor sensitivity is increased in the depressed phases of MDD and BD (Janowsky and Overstreet, 1990; Janowsky et al, 1994; Riemann et al, 1994b). Compatible with the findings of the current study, functional sex differences have been reported in baseline and cholinergically stimulated plasma hormone measures between major depressives and matched controls that suggest that heightened cholinergic sensitivity exists in premenopausal female, but not in male, patients with MDD (Riemann et al, 1994a; Rubin et al, 1999, 2003). Moreover, both functional neuroimaging (Cannon et al, 2006) and genetic (Comings et al, 2002) studies have implicated type 2 muscarinic cholinergic (M2) receptors in affective disorders. Specifically, Cannon et al (2006) reported that the distribution volume of the $\left[{ }^{18} \mathrm{~F}\right] \mathrm{FP}-\mathrm{TZTP}$, a PET radioligand that is relatively selective for $\mathrm{M} 2$ receptors, was reduced in bipolar depressives relative to controls, although the sample size was too small to permit assessment of sex effects. In unipolar depression, Wang et al (2004) showed associations between genetic variation in the CHRM2 gene and depression arising in families with an alcohol-dependent proband, whereas Comings et al (2002) found that genetic variation in the $3^{\prime}$ region of the CHRM2 gene (A/T 1890) was associated with MDD specifically in females. Taken together, these findings highlight the relevance of the muscarinic cholinergic system in depression and also appear complementary to the current report, as gender differences have been associated with both the genetic variation in the CHRM2 gene in MDD and now with the likelihood of experiencing an antidepressant response to scopolamine.

Previously, we proposed that the antidepressant effects of scopolamine may be mediated via interactions involving $\mathrm{N}$-methyl-D-aspartate glutamatergic receptors (NMDARs). Elevated glutamatergic transmission has been associated with the pathophysiology of depression, and a variety of antidepressant treatments have been shown to result in reduced NMDAR function (for review, see Paul and Skolnick, 2003). The NMDAR gene expression is enhanced by muscarinic receptor stimulation in at least some brain structures (Liu et al, 2004), and thus the elevated muscarinic receptor sensitivity identified in mood disorders (Janowsky et al, 1994) may contribute to an elevation in NMDAR transmission. Scopolamine administration reduces mRNA concentrations for NMDAR types $1 \mathrm{~A}$ and $2 \mathrm{~A}$ in rat brain (Liu et al, 2004) and via this mechanism may reduce NMDAR function.

Although the underlying mechanism that explains gender differences remains unclear, there are indications that hormones may have an important role in modulating the interactions between NMDAR function and M2 receptor stimulation. Estrogen has been shown to modulate the functional state of the cholinergic system by increasing choline acetyltransferase (ChAT) activity and by increasing the release of Ach (Gibbs et al, 2004; Pongrac et al, 2004). Researchers have also demonstrated that estrogen enhances NMDAR function by increasing NMDAR binding, at least in some brain regions, possibly by increasing the density of dendritic spines that express NMDAR (McEwen et al, 2001; Smith et al, 2009; Woolley and McEwen, 1994). Moreover, Daniel and Dohanich (2001) demonstrated that the influence of estrogen on NMDA receptor function is mediated specifically via $\mathrm{M} 2$ receptors.

The interactions among $\mathrm{M} 2$ receptors, NMDA receptors, and estrogen may indicate a direction for further study to evaluate the role of the cholinergic system in mood disorders, and the gender-based differences in the prevalence of depression. A variety of types of evidence have suggested that the cholinergic muscarinic receptors are hypersensitive in mood disorders, although the extent to which this finding extends to specific muscarinic subtypes has yet to be established. Nevertheless, if the muscarinic supersensitivity includes M2 receptors, this would be expected to increase NMDA receptor function (either via modulating gene expression and/or by increasing NMDA receptor density), consistent with the current understanding 
that increased glutamatergic activity is associated with depression. Thus, the reduction of NMDA receptor activity following the antagonism of $\mathrm{M} 2$ receptors with scopolamine conceivably could account for the antidepressant effects observed (Liu et al, 2004). More interesting in the context of the current paper is the role of estrogen in this complex interaction. Estrogen enhances the interaction between M2 and NMDA receptors to boost further NMDA receptor activity, a mechanism that may contribute to the increased prevalence of depression in women, as well as the greater antidepressant response to scopolamine in women than men. By blocking M2 receptors with scopolamine, the influence of estrogen on NMDA receptors presumably would be diminished, which should further reduce NMDAR activity. Although the relation between NMDA receptors and M2 receptors would also apply to mood disorders in men, the influence of estrogen would be substantially smaller and thus the magnitude of change would be reduced.

The muscarinic cholinergic system interacts with other neurotransmitter systems implicated in the pathophysiology of depression that are also influenced by gonadal steroids, and that may alternatively or additionally contribute to sex differences in the antidepressant response to scopolamine. Interactions between the muscarinic cholinergic and serotonergic systems are hypothesized to contribute to the pathogenesis of major depression (Overstreet et al, 1996, 1998). Multiple aspects of serotonergic system function are influenced by testosterone, progesterone, and/or estrogen, and these interactions are hypothesized to underlie sex differences in the clinical epidemiology and course of mood disorders (Benmansour et al, 2009; Gupta et al, 2007; Rubinow et al, 1998; Sell et al, 2008; Zhang et al, 2006). Such interactions conceivably may influence cholinergic-serotonergic interactions in a way that modulates antidepressant responses to scopolamine.

Similarly, catecholaminergic neurotransmitter systems have been implicated in the pathophysiology of mood disorders, and testosterone, progesterone, and/or estrogen have been shown to modulate catecholamine synthesis, release, degradation, and/or transport (Alonso-Solis et al, 1996; Lester et al, 2010; Thompson and Certain, 2005; Zhang et al, 2006). The muscarinic cholinergic system interacts with catecholaminergic neurotransmitter function such that alterations in the balance between systems may have major roles in the pathophysiology of mood disorders (Janowsky et al, 1972, 1983; Lester et al, 2010; Sarter et al, 1999). For example, reduced dopaminergic receptor transmission is hypothesized to underlie the impairment of reward seeking and motivated behavior in depression (reviewed in Drevets et al, 2008). Increased muscarinic receptor sensitivity in depression would be expected to result in reduced striatal dopaminergic release (Hartvig et al, 2002). In addition, ovarian steroids exert an antidopaminergic effect at both the pituitary and striatal levels, whereas androgens can reverse these effects (Alonso-Solis et al, 1996; Dluzen and Ramirez, 1989; Labrie et al, 1980). Thus, females conceivably may develop more prominently reduced dopaminergic transmission in association with muscarinic receptor supersensitivity than males. If so, then conversely females would be expected to show enhanced improvement in response to muscarinic antagonist administration than males. In summary, although the mechanisms underlying sex differences in the antidepressant response to scopolamine remain unclear, the prominent influence that gonadal steroids exert on a variety of neurobiological systems suggests that these mechanisms involve complex interactions involving multiple neurotransmitter systems.

Several features of the sample selection limit the generalizability of the current findings. First, the sample was relatively small for the male participants. Second, both elderly and pediatric subjects, and current nicotine users, were excluded from participation in the study, and thus the findings may not generalize to such cases. Smokers were excluded from participation because of concern regarding possible functional interactions between the muscarinic and nicotinic cholinergic receptor systems that could potentially influence the antidepressant effect of scopolamine. Finally, we used a single regimen for the administration of scopolamine.

The finding that males show a reduced antidepressant response to three pulses of scopolamine at $4 \mu \mathrm{g} / \mathrm{kg}$ i.v. may highlight the need to determine if males would experience added benefit from increasing the number of administrations or by using a larger dose of scopolamine. The dose used in this study varied based on body weight, but was the same for males and females. Future studies should focus on the evaluation of slightly higher doses of scopolamine in men.

\section{ACKNOWLEDGEMENTS}

We thank Mark Opal and Summer Peck for technical support, Michele Drevets and Joan Williams for patient recruitment and evaluation, David Luckenbaugh for statistical advice, and Paul Carlson, Alan Mallinger, Andy Speer, Carlos Zarate, Meena Vythilingam, and the 5SW Day Hospital nursing staff for medical support. This research was supported by the NIH NIMH-DIRP.

\section{DISCLOSURE}

The NIMH has filed a use-patent for the use of scopolamine in the treatment of depression, and Drs Furey and Drevets are identified as co-inventors on this pending patent application. The other authors declare no conflict of interest.

\section{REFERENCES}

Alonso-Solis R, Abreu P, Lopez-Coviella I, Hernandez G, Fajardo N, Hernandez-Diaz F et al (1996). Gonadal steroid modulation of neuroendocrine transduction: a transynaptic view. Cell $\mathrm{Mol}$ Neurobiol 16: 357-382.

American Psychiatric Association (2000). Diagnostic and Statistical Manual of Mental Disorders, IV, Text Revision. American Psychiatric Association: Washington DC.

Bebbington PE, Dunn G, Jenkins R, Lewis G, Brugha T, Farrell M et al (1998). The influence of age and sex on the prevalence of depressive conditions: report from the National Survey of Psychiatric Morbidity. Psychol Med 28: 9-19.

Benmansour S, Piotrowski JP, Altamirano AV, Frazer A (2009). Impact of ovarian hormones on the modulation of the serotonin 
transporter by fluvoxamine. Neuropsychopharmacology 34: 555-564.

Berlanga C, Flores-Ramos M (2006). Different gender response to serotonergic and noradrenergic antidepressants. A comparative study of the efficacy of citalopram and reboxetine. J Affect Disord 95: $119-123$.

Bland RC, Orn H, Newman SC (1988). Lifetime prevalence of psychiatric disorders in Edmonton. Acta Psychiatr Scand Suppl 338: 24-32.

Cannon DM, Carson RE, Nugent AC, Eckelman WC, Kiesewetter DO, Williams J et al (2006). Reduced muscarinic type 2 receptor binding in subjects with bipolar disorder. Arch Gen Psychiatry 63: 741-747.

Comings DE, Wu S, Rostamkhani M, McGue M, Iacono WG, MacMurray JP (2002). Association of the muscarinic cholinergic 2 receptor (CHRM2) gene with major depression in women. Am J Med Genet 114: 527-529.

Daniel JM, Dohanich GP (2001). Acetylcholine mediates the estrogen-induced increase in NMDA receptor binding in CA1 of the hippocampus and the associated improvement in working memory. J Neurosci 21: 6949-6956.

Dluzen DE, Ramirez VD (1989). Progesterone effects upon dopamine release from the corpus striatum of female rats. I. Evidence for interneuronal control. Brain Res 476: 332-337.

Drevets WC, Furey ML (2010). Replication of scopolamine's antidepressant efficacy in major depressive disorder: a randomized, placebo-controlled clinical trial. Biol Psychiatry 67: 432-438.

Drevets WC, Price JL, Furey ML (2008). Brain structural and functional abnormalities in mood disorders: implications for neurocircuitry models of depression. Brain Struct Funct 213: 93-118.

First MB, Spitzer RL, Gibbon M, Williams JBW (1997). Structured Clinical Interview for DSM-IV. American Psychiatric Press: Washington, DC.

Frackiewicz EJ, Sramek JJ, Cutler NR (2000). Gender differences in depression and antidepressant pharmacokinetics and adverse events. Ann Pharmacother 34: 80-88.

Furey ML, Drevets WC (2006). Antidepressant efficacy of the antimuscarinic drug scopolamine: a randomized, placebocontrolled clinical trial. Arch Gen Psychiatry 63: 1121-1129.

Gibbs RB, Gabor R, Cox T, Johnson DA (2004). Effects of raloxifene and estradiol on hippocampal acetylcholine release and spatial learning in the rat. Psychoneuroendocrinology 29: 741-748.

Goodnick PJ, Chaudry T, Artadi J, Arcey S (2000). Women's issues in mood disorders. Expert Opin Pharmacother 1: 903-916.

Gupta S, Mehrotra S, Villalon C, De Vries R, Garrelds I, Saxena P et al (2007). Effects of female sex hormones on responses to CGRP, acetylcholine, and 5-HT in rat isolated arteries. Headache 47: $564-575$.

Hamilton M (1959). The assessment of anxiety states by rating. Br J Med Psychol 32: 50-55.

Hartvig P, Nordberg A, Torstenson R, Sjoberg P, Fasth KJ, Langstrom B (2002). Interaction of a muscarinic cholinergic agonist on acetylcholine and dopamine receptors in the monkey brain studied with positron emission tomography. Dement Geriatr Cogn Disord 13: 199-204.

Hildebrandt MG, Steyerberg EW, Stage KB, Passchier J, Kragh-Soerensen P (2003). Are gender differences important for the clinical effects of antidepressants? Am J Psychiatry 160: $1643-1650$.

Janowsky DS, el-Yousef MK, Davis JM, Sekerke HJ (1972). A cholinergic-adrenergic hypothesis of mania and depression. Lancet 2: 632-635.

Janowsky DS, Overstreet DH (1990). Cholinergic dysfunction in depression. Pharmacol Toxicol 66(Suppl 3): 100-111.

Janowsky DS, Overstreet DH, Nurnberger Jr JI (1994). Is cholinergic sensitivity a genetic marker for the affective disorders? Am J Med Genet 54: 335-344.
Janowsky DS, Risch SC, Gillin JC (1983). Adrenergic-cholinergic balance and the treatment of affective disorders. Prog Neuropsychopharmacol Biol Psychiatry 7: 297-307.

Khan A, Khan SR, Shankles EB, Polissar NL (2002). Relative sensitivity of the Montgomery-Asberg Depression Rating Scale, the Hamilton Depression rating scale and the Clinical Global Impressions rating scale in antidepressant clinical trials. Int Clin Psychopharmacol 17: 281-285.

Kornstein SG, Schatzberg AF, Thase ME, Yonkers KA, McCullough JP, Keitner GI et al (2000). Gender differences in treatment response to sertraline versus imipramine in chronic depression. Am J Psychiatry 157: 1445-1452.

Labrie F, Ferland L, Veilleux R, Euvrard C, Boissier J (1980). Influence of estrogens on tuberoinfundibular and striatal dopaminergic systems in the rat. Acta Psychiatr Belg 80: 658-673.

Lester DB, Rogers TD, Blaha CD (2010). Acetylcholine-dopamine interactions in the pathophysiology and treatment of CNS disorders. CNS Neurosci Ther 16: 137-162.

Liu HF, Zhou WH, Xie XH, Cao JL, Gu J, Yang GD (2004). [Muscarinic receptors modulate the mRNA expression of NMDA receptors in brainstem and the release of glutamate in periaqueductal grey during morphine withdrawal in rats]. Sheng Li Xue Bao 56: 95-100.

Martenyi F, Dossenbach M, Mraz K, Metcalfe S (2001). Gender differences in the efficacy of fluoxetine and maprotiline in depressed patients: a double-blind trial of antidepressants with serotonergic or norepinephrinergic reuptake inhibition profile. Eur Neuropsychopharmacol 11: 227-232.

McEwen B, Akama K, Alves S, Brake WG, Bulloch K, Lee S et al (2001). Tracking the estrogen receptor in neurons: implications for estrogen-induced synapse formation. Proc Natl Acad Sci USA 98: 7093-7100.

McNair DM, Lorr M, Droppleman LF (1971). EITS Manual for the Profile of Mood States. Educational and Industrial Testing Service: San Diego, CA.

Nierenberg AA, DeCecco LM (2001). Definitions of antidepressant treatment response, remission, nonresponse, partial response, and other relevant outcomes: a focus on treatment-resistant depression. J Clin Psychiatry 62(Suppl 16): 5-9.

Overstreet DH, Daws LC, Schiller GD, Orbach J, Janowsky DS (1998). Cholinergic/serotonergic interactions in hypothermia: implications for rat models of depression. Pharmacol Biochem Behav 59: 777-785.

Overstreet DH, Miller CS, Janowsky DS, Russell RW (1996). Potential animal model of multiple chemical sensitivity with cholinergic supersensitivity. Toxicology 111: 119-134.

Paul IA, Skolnick P (2003). Glutamate and depression: clinical and preclinical studies. Ann NY Acad Sci 1003: 250-272.

Pinto-Meza A, Usall J, Serrano-Blanco A, Suarez D, Haro JM (2006). Gender differences in response to antidepressant treatment prescribed in primary care. Does menopause make a difference? J Affect Disord 93: 53-60.

Pongrac JL, Gibbs RB, Defranco DB (2004). Estrogen-mediated regulation of cholinergic expression in basal forebrain neurons requires extracellular-signal-regulated kinase activity. Neuroscience 124: 809-816.

Quitkin FM, Stewart JW, McGrath PJ (2001). Gender differences in treatment response. Am J Psychiatry 158: 1531-1533.

Riemann D, Hohagen F, Bahro M, Berger M (1994a). Sleep in depression: the influence of age, gender and diagnostic subtype on baseline sleep and the cholinergic REM induction test with RS 86. Eur Arch Psychiatry Clin Neurosci 243: 279-290.

Riemann D, Hohagen F, Krieger S, Gann H, Muller WE, Olbrich R et al (1994b). Cholinergic REM induction test: muscarinic supersensitivity underlies polysomnographic findings in both depression and schizophrenia. J Psychiatr Res 28: 195-210.

Rubin RT, Abbasi SA, Rhodes ME, Czambel RK (2003). Growth hormone responses to low-dose physostigmine administration: 
functional sex differences (sexual diergism) between major depressives and matched controls. Psychol Med 33: 655-665.

Rubin RT, O'Toole SM, Rhodes ME, Sekula LK, Czambel RK (1999). Hypothalamo-pituitary-adrenal cortical responses to low-dose physostigmine and arginine vasopressin administration: sex differences between major depressives and matched control subjects. Psychiatry Res 89: 1-20.

Rubinow DR, Schmidt PJ, Roca CA (1998). Estrogen-serotonin interactions: implications for affective regulation. Biol Psychiatry 44: 839-850.

Sarter M, Bruno JP, Turchi J (1999). Basal forebrain afferent projections modulating cortical acetylcholine, attention, and implications for neuropsychiatric disorders. Ann NY Acad Sci 877: 368-382.

Sell SL, Craft RM, Seitz PK, Stutz SJ, Cunningham KA, Thomas ML (2008). Estradiol-sertraline synergy in ovariectomized rats. Psychoneuroendocrinology 33: 1051-1060.

Smith CC, Vedder LC, McMahon LL (2009). Estradiol and the relationship between dendritic spines, NR2B containing NMDA receptors, and the magnitude of long-term potentiation at hippocampal CA3-CA1 synapses. Psychoneuroendocrinology 34(Suppl 1): S130-S142.
Steiner M, Dunn E, Born L (2003). Hormones and mood: from menarche to menopause and beyond. J Affect Disord 74: 67-83.

Thompson TL, Certain ME (2005). Estrogen mediated inhibition of dopamine transport in the striatum: regulation by $\mathrm{G}$ alpha i/o. Eur J Pharmacol 511: 121-126.

Wang JC, Hinrichs AL, Stock H, Budde J, Allen R, Bertelsen S et al (2004). Evidence of common and specific genetic effects: association of the muscarinic acetylcholine receptor M2 (CHRM2) gene with alcohol dependence and major depressive syndrome. Hum Mol Genet 13: 1903-1911.

Woolley CS, McEwen BS (1994). Estradiol regulates hippocampal dendritic spine density via an N-methyl-D-aspartate receptordependent mechanism. J Neurosci 14: 7680-7687.

Yonkers KA (2003). Special issues related to the treatment of depression in women. J Clin Psychiatry 64(Suppl 18): 8-13.

Young RC, Biggs JT, Ziegler VE, Meyer DA (1978). A rating scale for mania: reliability, validity and sensitivity. Br J Psychiatry 133: 429-435.

Zhang Z, Chen K, Shih JC, Teng CT (2006). Estrogen-related receptors-stimulated monoamine oxidase $\mathrm{B}$ promoter activity is down-regulated by estrogen receptors. Mol Endocrinol 20: $1547-1561$.

Supplementary Information accompanies the paper on the Neuropsychopharmacology website (http://www.nature.com/npp) 